Anat. Inst. d. Mediz. Fak., Univ. Okayama (Vorstand: Prof. M. SEKI).

\title{
Färbung der tuberkulösen Herde mit lipoidfärbendem Viktoriablau.
}

\author{
結核巣を類脂質を染めるビクトリア青で染色.
}

Tetsu KARIYA 特 谷哲.

(Eingegangen am 29. Dezember 1955.)

Die Tatsache, daß in den sich regressiv ändernden tuberkulösen Herden Fett und Lipoide reichlich erscheinen, hat schon früher große Beachtung gefunden. Z. B. haben PAGEL (1925) und KUTSUKAKE (1928) bemerkt, daß Fett und Lipoide je nach den Typen der Krankheit in verschiedenen Weisen auftreten, wobeı die Lipoide nach der Methoden von CIACCIO und SMITH-DIETRICH untersucht wurden. Die Untersuchungen in der Folgezeit wurden auch meistens nach diesen Methoden durchgeführt. Danach behandelt man aber die Gewebe mit stark oxydierendem Kaliumbichromat. Dieses Mittel greift die Lipoproteine im Gewebe an und demaskiert Lipoide, wie der Verfasser (1955) an den Leberzellen gezeigt hat. In dem mit einer bichromathaltigen Flüssigkeit fixierten Material können also Lipoide, verglichen mit den natürlichen Zuständen, weitaus mehr nachgewiesen werden.

Zur Darstellung der in tuberkulösen Herden in der Natur auftretenden freien Lipoide empfiehlt sich eine Färbung des formalinfixierten Materials mit dem mittelstark polaren, sog. alkohollöslichen Farbstoff Viktoriablau. Es wurde also folgende Untersuchung unternommen.

\section{Material und Methode.}

Es wurde Material der tuberkulös erkrankten Lunge bei Gelegenheit der Pneumektomie entnommen, zum Teil aber auch aus sezierten Leichen gewonnen. Nach der Fixierung in Formalin zerlegte man das Material in $15 \mu$ dicke Gefrierschnitte. Die auf dem Objektglas nach der LEACHschen Methode aufgeklebten Schnitte wurden mit $0.01 \%$ iger wässeriger Viktoriablaususpension bei $37^{\circ} \mathrm{C} 30$ Minuten lang gefärbt. Manchmal wurden sie mit Kernechtrot nachgefärbt. Man schloß die Schnitte nach Wasserausspülung im Gummisirup ein und mikroskopierte sie.

Man bereitete die $0.01 \%$ ige Viktoriablaususpension vor dem Gebrauch in der Weise, daß man eine 1\% ige alkoholische Lösung von Viktoriablau von MERCK mit einem Gummiarabikum $0.5 \%$ ig in sich enthaltendem Wasser $100 \mathrm{fach}$ verdünnte. Das Gummiarabikum spielte bis zu einem gewissen Grade die Rolle des Schutzkolloides, um eine Vergröberung von 
Viktoriablauteilchen zu verhindern.

Zur Kontrolle wurden die Schnitte mit Sudanschwarz B, mit Sudan III, nach CIACCIO, nach SMITH-DIETRICH und nach der ZIEHL-NEELSENschen Tuberkelbazillenfärbung u. a. gefärbt und vergleichend beobachtet.

\section{Ergebnisse der Untersuchung.}

Das histologische Bild der Lungentuberkulose ist sehr mannigfaltig, und man sieht oft selbst in ein und derselben Lunge frische und alte tuberkulöse Herde nebeneinander. Im folgenden werden die Herde in drei Hauptgruppen eingeteilt; nämlich in exsudative, produktive und veraltete sklerosierte Herde.

\section{A. Der exsudative Herd.}

In den Lungenalveolen in den beginnenden exsudativen Herden kommen viele Zellen vor, unter denen sog. große Exsudatzellen gefunden werden. Thr Cytoplasma wird gewöhnlich mit Viktoriablau gleichmäßig, aber nur schwach blau färbbar. Ihr Kern färbt sich nicht gut. In den vergrößerten Herden etwas späterer Stadien treten im schwach blauen Cytoplasma der großen Exsudatzellen mehr oder weniger stark blau gefärbte Granula auf. (Abb. 1 u. 2). Diese Granula treten im Anfang um den Kern als feine Körperchen auf und scheinen mit Vermehrung der Zahl sich miteinander zu verschmelzen und gröber zu werden. Sie umgeben zuweilen Vakuolen und verschmelzen sich miteinander. Die hier als große Exsudatzellen aufgefassten Zellen sind zum größeren Teil Histiocyten, und die übrigen sind zumeist Fibrohistiocyten und Monocyten. Die mit Viktoriablau färbbaren Granula sind in den Histiocyten zahlreich

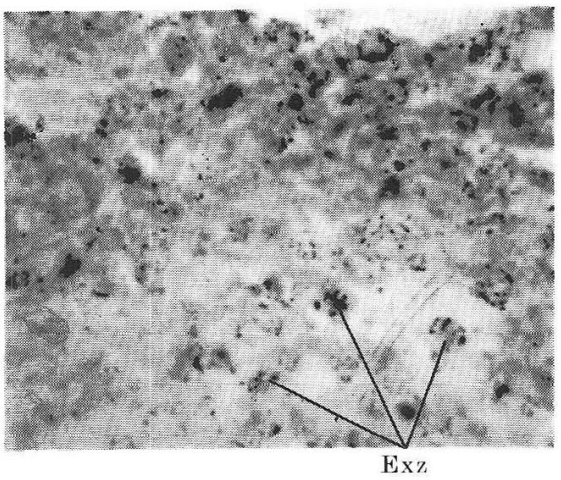

Abb. 1. Aus einem exsudativen tuberkulösen Herd. Viktoriablaufärbung. Große Exsudatzellen $(\boldsymbol{E} \boldsymbol{x} \boldsymbol{z})$ speichern stark gefärbte Granula auf. $500 x$. 


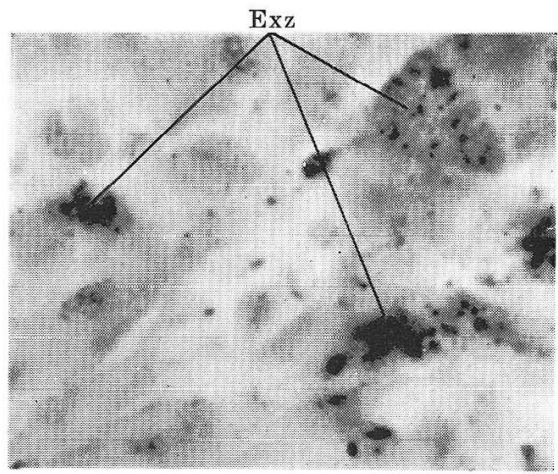

Abb. 2. Starke Vergrößerung eines Teils der Abb. 1. $1250 \times$.

und verschieden groß, in den Fibrohistiocyten und Monocyten aber weniger zahlreich und feiner.

In fortgeschrittenen Krankheitsherden finden sich mit Viktoriablau stark färbbare Granula von verschiedener Größe sehr zahlreich. Sie sind nicht nur innerhalb, sondern auch außerhalb der Zellen zu sehen. Solche lipoiden Granula kommen besonders reichlich in verkäsenden Herden vor. Solche Herde färben sich, wie in Abb. 3 gezeigt wird, im ganzen mittelstark blau, und in ihnen kommen stark gefärbte, fein granuläre oder grob tropfenförmige Gebilde unregelmäßig angehäuft vor. Bei genauerer

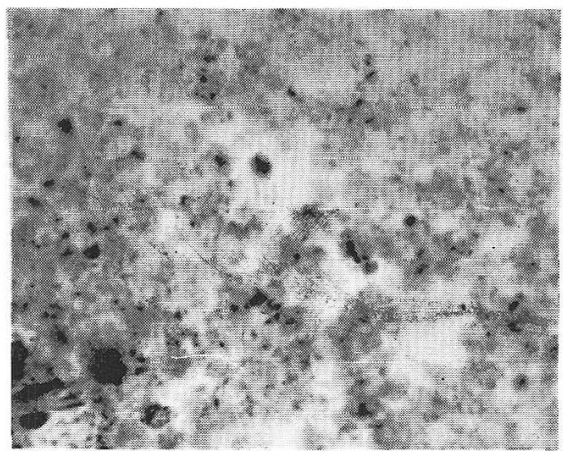

Abb. 3. Aus einem 'Teil der beginnenden Verkäsung in einem exsudativen Herd. Viktoriablaufärbung. In dem mittelstark blau kolorierten Grund liegen zahlreiche, stark gefärbte Granula und Tröpfchen von verschiedener Größe. $500 \times$.

Beobachtung beobachtet man unter den so stark gefärbten Gebilden solche, die zweifelsohne in Verkäsung verfallene Zellen sind. Solche verkäsenden 
Herde wurden mit Sudan III, nach CIACCIO, nach SMITH-DIETRICH und mit Sudanschwarz B stark gefärbt.

Die Färbbarkeit des Herdes mit Viktoriablau nimmt mit dem Fortschreiten der Verkäsung merkwürdigerweise wieder etwas ab. In den verkästen Stellen sieht man immer noch stark gefärbte tropfenförmige Gebilde (Abb. 4). Mit Sudan III, nach CIACCIO, nach SMITH-DIETRICH und mit Sudanschwarz färbt sich die Verkäsung stärker.

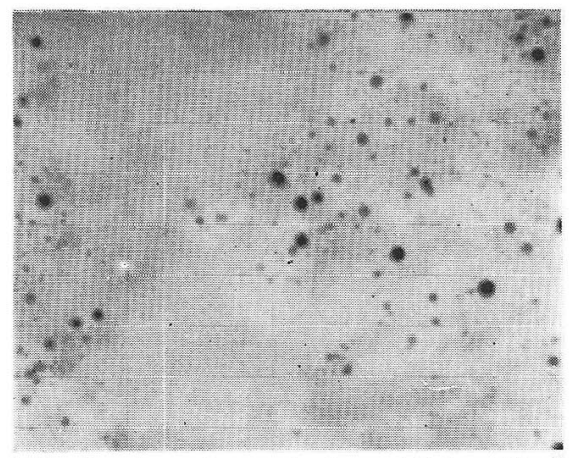

Abb. 4. Aus einem stark verkästen Herd.

Die Grundsubstanz ist mit Viktoriablau schlecht färbbar. $500 \times$.

\section{B. Der produktive Herd.}

Die Pathologen bezeichnen die größeren, rundlichen, mit reichlichem Cytoplasma versehenen Zellen im tuberkulösen Herde als Epitheloidzellen (z. B. CASTREN 1923). Sie sind zum größten Teil nichts anderes als abgerundete Histiocyten oder vergrößcrte Monocyten. Die typische produktive Tuberkel hat eine Verkäsung in der Mitte, welche von einer Schicht von Epitheloidzellen und Riesenzellen umgeben ist. Mit Viktoriablau färbt sich die Verkäsung, wie in Abb. 5 dargestellt ist, diffus mäßig blau, aber stellenweise granulös stark blau. Die Riesenzellen werden stark gefärbt. Der äußere Teil der Tuberkel wird hauptsächlich durch kleine Lymphocyten, Monocyten und Plasmazellen infiltriert. Diese kleinen Rundzellen in der äußeren Teil der Tuberkel sind überhaupt nicht gut färbbar.

Die Färbbarkeit der Verkäsung des produktiven Herdes ist fast die gleiche wie beim exsudativen Herd. In der Grenze zwischen dem verkästen Anteil des Herdes und der Epitheloidzellenschicht ordnen sich Zellen mit verschieden großen, mit Viktoriablau stark gefärbten Granula palisadenartig (Abb. 6). Sie sind spindelförmig bis rundlich an Gestalt und gehören auch zu den Epitheloidzellen (Abb. 7 u. 8). Zwischen diesen Zellen liegen blau gefärbte Klümpchen und Granula von der gleichen 


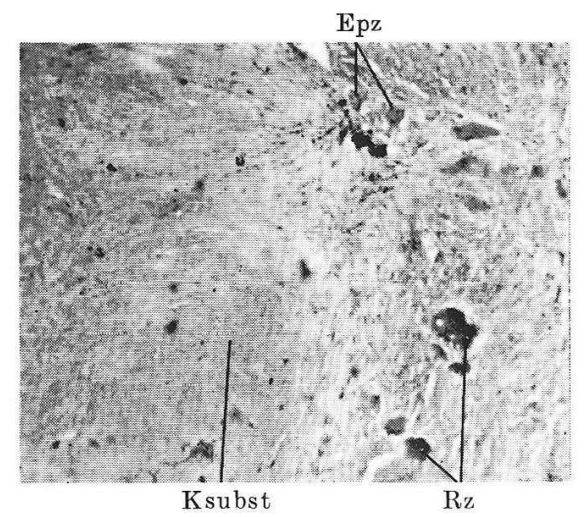

Abb. 5. Aus einer produktiven Tuberkel. Viktoriablaufärbung. In dem linken Abschnitt Verkäsung (Ksubst). Epitheloidzellen ( $E p \boldsymbol{z})$ und Riesenzellen $(R \boldsymbol{z})$ beladen sich mit stark gefärbten Granula. $125 \times$.

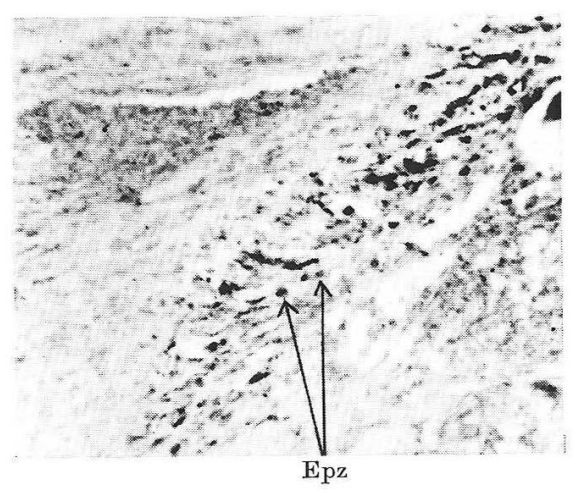

Abb. 6. Aus einer produktiven Tuberkel. Viktoriablaufärbung. Palisadenartige Anordnung von Epitheloidzellen $(E p z)$ mit stark gefärbten Granula. $250 \times$.

Natur wie die in den Zellen (Abb. 9), nur daß die Granula in den Zellen meist feiner und stärker blau gefarbt sind, während die außerhalb der Zellen liegenden meist größer, tropfenförmig und schwächer färbbar sind. Die weiter außen vorhandenen Epitheloidzellen färben sich schwächer blau und schließen weniger stark blau färbbare Granula ein. Die hier als Epitheloidzellen bezeichneten sind zum größten Teil Histiocyten und Monocyten. Unter ihnen enthalten die Histiocyten am reichlichsten blau färbbare Guanula. 


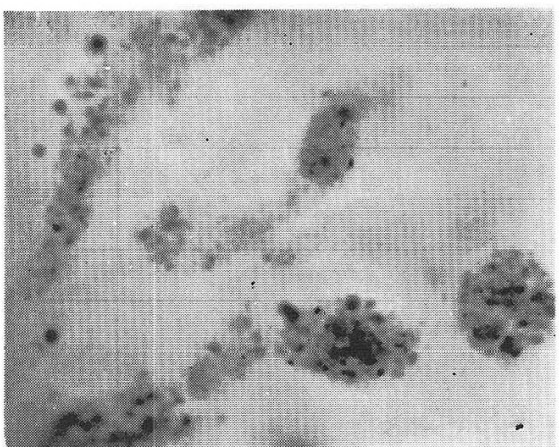

Abb. 7. Aus einer produktiven Tuberkel. Viktoriablaufärbung. Spindelförmige Epitheloidzellen mit reichlichen, stark gefärbten Granula. $1250 \times$

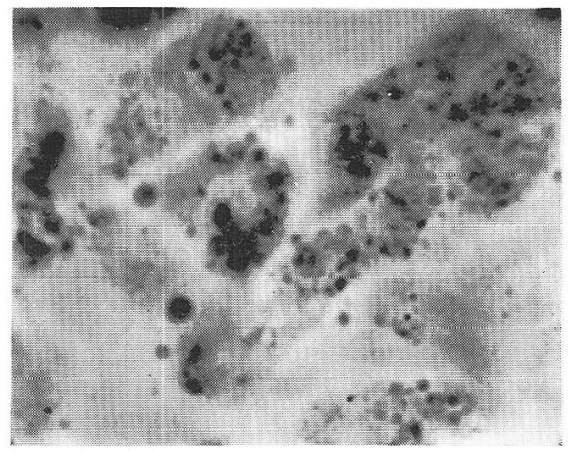

Abb. 8. Wie bei Abb. 7. Die rundlichen Epitheloidzellen mit stark gefärbten Granula. $1250 \times$.

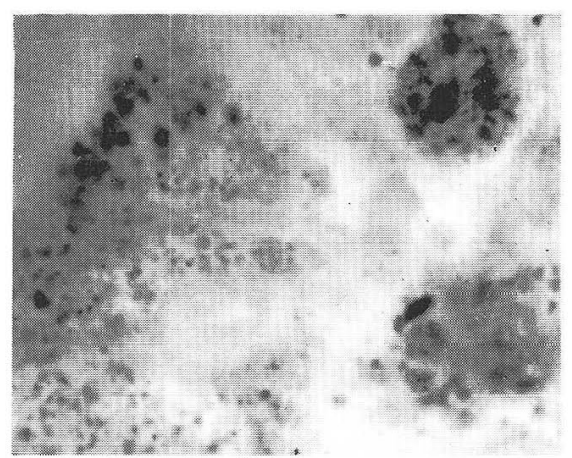

Abb. 9. Aus der äußeren Grenze der Verkäsung. Viktoriablaufärbung. Die mit stark färbbaren Granula vollpfropften Zellen gehen unter und zerfallen. $1250 \times$. 
Unter den Riesenzellen gibt es solche, deren Grundplasma sich diffus blau färbt. Thre stark gefärbten Granula finden sich meist im Randteil der Zellen, während sie in der Mitte des Zelleibes nicht oder kaum vorhanden sind (Abb. 10).

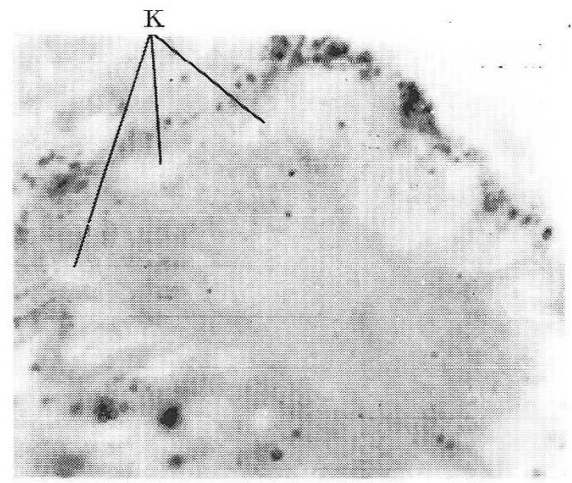

Abb. 10. Eine Riesenzelle aus einer produktiven Tuberkel. Viktoriablaufärbung. Die stark gefärbten Granula liegen zahlreich auf der äußeren Seite der Kerne. Die Kerne $(K)$ sind mit Viktoriablau kaum zu färben, $1250 \times$.

Die kleinen Rundzellen in dem peripheren Teil der Tuberkel sind Lymphocyten, Monocyten und Plasmazellen. Sie sind mit Viktoriablau nicht gut färbbar. Die Zusammen mit ihnen vereinzelt vorhandenen Histiocyten und Monocyten beladen sich mit Viktoriablaugranula (Abb. $11)$.

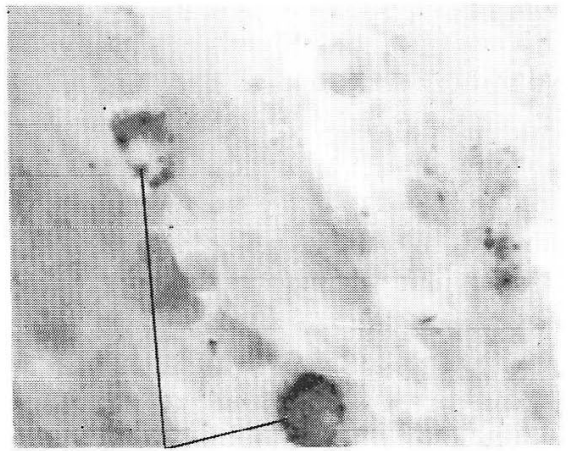

Mne od. Hsc

Abb. 11. Aus einer produktiven Tuberkel. Viktoriablaufärbung. Monocyten ( $M n c$ ) und Histiocyten ( $H s c$ ) mit stark gefärbten Granula. $1250 \times$. 


\section{Der veraltete Herd.}

Die Verkäsung im centralen Teil des Herdes wird mit Viktoriablau nicht mehr gut gefärbt. Auch ist sie mit Sudan III, nach CIACCIO, nach SMITH-DIETRICH und mit Sudanschwarz B schwach färbbar. Sie scheint also an Lipoiden, sowie an neutralem Fett ärmer geworden zu sein. In der bindegewebigen Kapsel um die Verkäsung speichern die als Fibrocyten und Fibrohistiocyten angesehenen Zellen mit Viktoriablau stark färbbare Granula auf (Abb. 12).

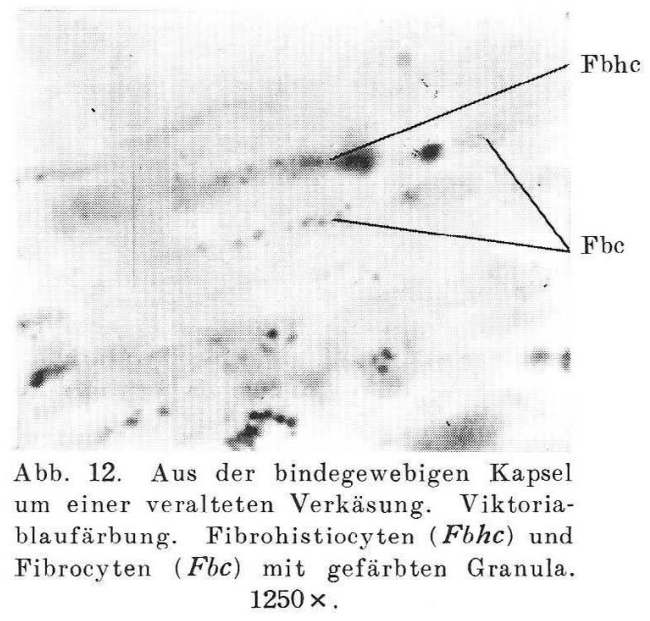

III. Auswertung der Ergebnisse.

Die großen Exsudatzellen und Monocyten im exsudativen Herde, die Epitheloidzellen, Riesenzellen und Monocyten im produktiven Herde und die Fibrocyten und Fibrohistiocyten in der bindegewebigen Kapsel des veralteten Herdes schließen mit Vikțoriablau stark färbbare Granula reichlich ein. Auch im verkästen Teil des Herdes sind mit Viktoriablau stark färbbare Granula und Tröpfchen zahlreich vorhanden.

Die oben erwähnten, mit Viktoriablau färbbaren Gebilde sind natürlich von lipoider Natur und scheinen größtenteils aus Lipoproteinen in degenerierten Zellen abgespaltet zu sein.

Bedenkt man ferner, daß BERMANN (1952) die Tuberkelbazillen in Auswurf, Eiter, Harn, Cerebrospinalflüssigkeit usw. und die kultivierten Tuberkelbazillen mit fett- und lipoidfärbendem Sudanschwarz färbte, und, daß MII (1955) die von Histiocyten phagocytierten Tuberkelbazillen mit lipoidfärbendem Viktoriablau färbte, so darf man annehmen, daß die Lipoide zum Teil von den Tuberkelbazillen herrühren.

Fis erübrigt sich nur noch, den Grund hinzufügen, warum Sudan- 
schwarz B Gebilde in größerer Zahl färbt als Viktoriablau. Die leichte Löslichkeit von Sudanschwarz B in Ricinusöl, Cedernöl, Xylol u. dgl. macht es verständlich, daß seine Moleküle schwächer polar sind als die von Viktoriablau. Ein solcher Farbstoff löst sich auch in Neutralfett und färbt also in ausgedehnterem Maß.

$\mathrm{Zu}$ bemerken ist ferner, daß der veraltete käsige Herd an freien Lipoiden und Fetten ärmer ist als der noch nicht veraltete, weil der erstere sowohl mit Viktoriablau, als auch mit Sudan III schwächer färbbar ist.

\section{Zusammenfassung.}

Es wurden Stücke von tuberkulös erkrankter Lunge mit Formalin fixiert und in Gefrierschnitte zerlegt. Die Schnitte wurden mit lipoidfärbendem, mittelstark polarem Viktoriablau, mit schwächer polarem Sudanschwarz B und mit am schwächesten polarem Sudan III sowie nach CIACCIO und SMITH-DIETRICH gefärbt.

1. Im exsudativen Herd kommen Histiocyten, Fibrohistiocyten und Monocyten als große Exsudatzellen vor. Die Histiocyten speichern mit Viktoriablau färbbare Granula am reichlichsten auf.

2. In dem verkästen Teil des produktiven Herdes sieht man Haufen von mit Viktoriablau färbbaren Granula. Dieser verkäste Teil wird von einer Schicht von Histiocyten und Monocyten umgeben. Diese Zellen enthalten mit Viktoriablau färbbare Granula von verschiedener Größe. Nach außen werden die in Zellen enthaltenen, mit Viktoriablau färbbaren Granula immer spärlicher. Die Riesenzellen zeigen solche Granula hauptsächlich im Randteil des Zelleibes.

3. In dem sklerosierten Herde wird der verkäste Teil sowohl mit Viktoriablau, als auch mit Sudan III schlecht färbbar. Dieser Teil scheint an freien Lipoiden und Fett ärmer geworden zu sein.

4. Die Färbbarkeit eines Gebildes mit Viktoriablau, Sudanschwarz B, Sudan III, sowie nach CIACCIO und SMITH-DIETRICH ist zwar verschieden. Die Stärke der Färbung verschiedener Gebilde verläuft aber in den erwähnten Färbungsweisen im wesentlichen parallel.

\section{內 容自 抄.}

結核飞罹患した肺組織をホルマリンで固定し，凍結切片にし，類脂質を 染める中等極性の染料ビクトリア青, 弱極性の染料ズダン黒 B, 無極性の 染料ズダンIII で，又 Ciaccio と Smith-Dietrich の染色法に従って染め, 比較観察した。

1. 滲出性病巣では大滲出細胞として組織球，線組球，単球が出現する. そのうち組織球がビクトリア青に染をる粒子を最も多く持つ. 
2. 増殖性病巣の乾酪化部にビクトリア青に染まる粒子が多く見られる. この様な乾酪化部は組織球や単球で囲まれ，それ等の細胞は種々の大さの ビクトリア青に染まる粒子を持つ。そして細胞内のビクトリア青に染まる 粒子は病巣の外方へ行くほど少い. 巨大細胞ではビクトリア青飞染まる粒 子が主に細胞体の辺縁部に見られる。

3. 硬化性病巣飞於ては乾酪化部はビクトリア青のみならずズダン III での染まり方も悪い，従ってこの部は遊離の類脂質と脂肪にそしいと思わ れる。

4. 1つの物象のビクトリア青, ズダン黑 B, ズダン III, Ciaccio, SmithDietrich での染まり方は違うが，種々の物象のそれ等の染色法での染りの 強さは大体平行する.

\section{Literatur.}

Bermann, R. : Die Färbung der Tuberkelbazillen mit Sudanschwarz BN. Z. Hyg. 134 (1952). - Castren, H. : Studien über die Struktur der Fibroblasten, Epitheloidzellen und Riesenzellen des tuberkulösen Gewebes beim Menschen. Arb. path. Inst. Univ. Hersingfors. N. F. 3 (1923). - Kariya, T.: Vergleichende Untersuchung über die demaskierende Wirkung der Fixierungsflüssigkeiten auf die lipoide Substanz der Leberzellen. Arch. hist. jap. 8 (1955). — Kōyama, Y.: Versuche der Färbung von Ölen und Fetten mit alkohollöslichen Farbstoffen (Jap. m. dtsch. Zfass.) Arch. hist. jap. 1 (1950). - Kutsukake, R. : Über das Fett im tuberkulösen Gewebe. (Jap.) Tokyo med. J. 52 (1928). - Mii, Y.: Veränderungen der Färbbarkeit mit Viktoriablau der in den Bindegewebszellen aufgenommenen Tuberkelbazillen BCG. Arch. hist. jap. 8 (1955). - Pagel, W. M. : Zur Histochemie der Lungentuberkulose mit besonderer Berücksichtigung der Fettsubstanzen und Lipoide. Virchows Arch. 256 (1925). 